\title{
A DIMENSÃO JURÍDICO-CONSTITUCIONAL NA FORMULAÇÃO DE POLÍTICAS PÚBLICAS: UMA PERSPECTIVA A SER EXPLORADA
}

\author{
MANOEL ADAM LaCAyo VALENTE*
}

1. Introdução. 2. A formulação de politicas públicas no paradigma democrático tradicional que caracteriza os países periféricos. 3. A formulação de políticas públicas e o novo paradigma de democracia combinada. 4. A democracia da participação e o controle jurisdicional da formulação de políticas públicas. 5. Conclusão. 6. Bibliografia.

\section{Introdução}

É fato inconteste que o regime político da democracia representativa enfrenta uma forte crise de legitimidade e de credibilidade. A ausência da legitimidade decorre da clara percepção dos detentores do poder político (os cidadãos) de que seus representantes atuam de maneira distanciada dos programas político-partidários que determinaram suas escolhas eleitorais. A ausência de credibilidade é acentuada pelos permanentes descumprimentos de "promessas" de campanha e pelas freqüentes formação de "alianças casuísticas" para enfrentamento, também, de questões casuísticas. Essa crise que contribui para a erosão da credibilidade do sistema de representação democrática se projeta sobre o desempenho dos mandatários populares e, por conseqüência, tem reflexos expressivos no processo de formulação de políticas públicas.

Paul Hirst, em seu livro "A Democracia Representativa e Seus Limites", aponta o caráter dual que caracteriza as democracias representativas com as seguintes palavras:

* Bacharel em Direito, com habilitação em Direito Público, bacharel em Comunicação Social, Mestre em Sociologia pela Universidade de Brasília, na linha de pesquisa da Sociologia Política, Consultor Legislativo, da área de Direito Administrativo e de Administração Pública da Consultoria Legislativa da Câmara dos Deputados, e Advogado.

R. Dir. Adm., Rio de Janeiro, 239: 127-138, Jan./Mar. 2005 
"As democracias representativas ocidentais são uma curiosa mistura de sucesso e fracasso. São bem-sucedidas no nivel de legitimação da autoridade governamental, mas ao preço de um baixo nível de participação do cidadão e de um baixo nível de efetiva fiscalização do processo de tomada de decisão governamental." (Hirst, 1992, 12-13).

Boaventura de Sousa Santos situa, na atualidade, o debate sobre a crise da democracia na dimensão qualitativa:

"Todos esses elementos que poderiam ser apontados como constituintes de uma concepção hegemônica da democracia não conseguem enfrentar adequadamente o problema da qualidade da democracia, que voltou à tona com a assim chamada 'terceira onda de democratização'. Quanto mais se insiste na fórmula clássica da democracia de baixa intensidade menos se consegue explicar o paradoxo de a extensão da democracia ter trazido consigo uma enorme degradação das práticas democráticas. Aliás, a expansão global da democracia liberal coincidiu com uma grande crise desta nos países centrais onde mais se tinha consolidado, uma crise que ficou conhecida como a da dupla patologia: a patologia da participação, sobretudo em vista do aumento dramático do abstencionismo; e a patologia da representação, o fato de os cidadãos se considerarem cada vez menos representados por aqueles que elegeram." (Boaventura de Sousa Santos, 2002, p. 42).

A configuração da crise da democracia representativa, segundo Antonio Carlos Wolkmer, "vem acompanhada de uma crise maior da própria política expressa pela perda de eficácia e confiabilidade nos partidos políticos, na administração estatal, no legislativo e no poder judiciário". (Wolkmer, 2001, p. 87).

Daniel García Delgado (1998,131-143) elencou seis causas que procuram explicar a crise da democracia representativa. Essas causas são as seguintes:

1. Sucessivos descumprimentos dos programas eleitorais.

2. Corrupção da classe política.

3. Declínio de vastos setores sociais, com a percepção de que a classe política é responsável pela ampliação da pobreza.

4. Complexidade das demandas e baixa especialização técnica para enfrentar desafios das sociedades modernas.

5. Crise dos grandes discursos de legitimação das formas de ação política.

6. Influência dos meios de comunicação.

Além da dinâmica interna, a crise da democracia também se relaciona com a ordem transnacional pós-moderna, fundada na ação do capitalismo globalizado e na agenda política neoliberal adotada pelas instituições multilaterais de "ajuda" financeira. Com efeito, entendida como "a expansão sem limites das corporações transnacionais na economia mundial", a globalização pôs em xeque uma das mais 
significativas características dos Estados modernos, qual seja a relacionada com a soberania desses entes nacionais, com reflexos incidentes em seus regimes político-representativos.

Ninguém desconhece que a "colaboração" financeira, oferecida pelas agências multilaterais de desenvolvimento, implica a aceitabilidade de políticas inflexíveis de ajuste e reforma econômica definida por aqueles organismos (Santos, 2001, p. 729). A submissão aos programas reformistas das agências multilaterais tem como consequuência, para os países tomadores de empréstimos, a minimalização da sua autonomia governamental, o que rompe com a sistemática da democracia representativa que só confere legitimação para atuação política aos escolhidos pelo voto popular. Esses novos atores, intervenientes na gestão pública dos Estados-nação, usurpam dos parlamentos nacionais a sua capacidade de condução político-institucional. A agenda de "constrangimentos" dos organismos multilaterais de desenvolvimento retira das autoridades eleitas o controle sobre decisões governamentais referentes à formulação de políticas públicas, o que fere de morte o âmago da democracia representativa, qual seja, o da legitimidade de representação pelo voto.

\section{A formulação de políticas públicas no paradigma democrático tradicional que caracteriza os paises periféricos}

O modelo político tradicional de democracia representativa, em países periféricos da América Latina, é fortemente marcado pela concepção patrimonialista. Com efeito, nesses países e, inclusive, no Brasil, a distinção entre a coisa pública e a esfera privada nem sempre foi muito nítida, o que, ao longo de séculos, permitiu a constituição de uma sociedade desigual em termos políticos e em níveis econômicos. A apropriação política do aparelho do Estado por elites populistas, com as suas práticas nepóticas e clientelísticas, proporcionou a consolidação de um sistema governamental que afastou da arena do poder o cidadão, em detrimento da figura do "pedinte e dependente de favores públicos". Nesse cenário, as diferenças entre governo e Estado, entre representantes políticos e detentores originais do poder e, essencialmente, entre res publica e patrimonialismo foram, propositalmente, escamoteadas com o fito de permitir a captura da máquina estatal por elites dominantes que, ao contrário de conduzir o Estado a servir ao povo, passaram a se servir do Estado para atendimento de seus interesses privados (Bursztyn, 1989).

Nesse contexto, a formulação de políticas públicas encontra-se contaminada, enquanto processo, pelo enfoque privatístico dos seus idealizadores, nem sempre traduzindo verdadeiras prioridades da sociedade. O Estado é apropriado como uma sesmaria normativa, cuja máquina funcional volta-se para a satisfação da vontade daqueles que, transitoriamente, representam, por delegação, o poder popular. É o fenômeno que se convencionou chamar como "privatização do Estado". Esse fenômeno foi amplamente estudado por Raymundo Faoro em sua obra clássica "Os Donos do Poder: formação do patronato político brasileiro" (2001). Nesse modelo de democracia representativa de "baixa intensidade", a formulação de políticas 
públicas é exercida, centralizadamente, em núcleos do poder sem a participação da sociedade civil e, em regra, a sua institucionalização legislativa dá-se por instrumentos jurídicos de exceção (decretos-lei, medidas provisórias, leis delegadas, etc.) (O’Donnell, 1991, 38).

Discorrendo sobre a nova administração pública, Luiz Carlos Bresser Pereira comenta o patrimonialismo e a privatização do Estado com as seguintes palavras (Bresser Pereira, 1997, p. 10-11):

"A característica que definia o governo nas sociedades pré-capialistas e pré-democráticas era a privatização do Estado, ou a confusão dos patrimônios públicos e privado. 'Patrimonialismo' significa a incapacidade ou a relutância do príncipe distinguir entre o patrimônio público e seus bens privados. A administração do Estado pré-capitalista era uma administração patrimonialista. Com o surgimento do capitalismo e da democracia, veio a se estabelecer uma distinção clara entre res publica $e$ bens privados. A democracia e a administração pública burocrática emergiram como as principais instituições que visavam proteger o patrimônio público contra a privatização do Estado. Democracia é o instrumento político que protege os direitos civis contra a tirania, que afirma os direitos políticos de votar $e$ ser votado, que assegura os direitos sociais contra a exploração, e que afirma os direitos públicos em relação à res publica. Burocracia é a instituição administrativa que usa como instrumento para combater o nepotismo e a corrupção - os princípios de um serviço público profissional, e de um sistema administrativo impessoal, formal, legal e racional.

Se, nos países desenvolvidos, os direitos individuais (civis e políticos) $e$ direitos sociais estavam razoavelmente protegidos, os direitos públicos não estavam: a res publica continuava exposta a todo tipo de ameaças. É certo que o nepotismo e a corrupção mais visíveis foram controlados, mas surgiram novas modalidades de apropriação privada do patrimônio público. Empresários continuavam a obter subsídios desnecessários e isenção de impostos; a classe média assegurava para si benefícios especiais muito maiores do que está disposta a reconhecer; os funcionários públicos eram muitas vezes ineficientes no trabalho, ou simplesmente não trabalhavam — quando ocorre excesso de quadros - mas se mantinham protegidos por leis ou costumes que lhes garantem a estabilidade no emprego."

3. A formulação de políticas públicas e o novo paradigma de democracia combinada

Como exposto nos segmentos anteriores é patente que a democracia representativa enfrenta uma crise de legitimidade. Contudo, em função das dimensões populacionais dos Estados modernos torna-se materialmente inviável um retorno ao modelo da democracia direta, no qual, sem mediação de representantes, o povo 
exercia, diretamente, em assembléia, o poder. Assim, à luz dessa realidade fática, o aperfeiçoamento do paradigma da democracia representativa e não o seu descarte é o desafio presente no contexto da teoria democrática contemporânea.

A combinação do sistema representativo com a modalidade de exercício político participativo consubstancia o novo paradigma de democracia para sociedades complexas.

Boaventura de Sousa Santos (1996, p. 270-271) aponta que a renovação da teoria democrática passa, necessariamente, pela articulação entre democracia representativa e democracia participativa. As palavras de Boaventura são as seguintes:

"A democracia representativa constituiu até agora o máximo de consciência política possivel do capitalismo. Este máximo não é uma quantidade fixa, é uma relação social. A complementação ou o aprofundamento da democracia representativa através de outras formas mais complexas de democracia pode conduzir à elasticização e aumento do máximo de consciência possível, caso em que o capitalismo encontrará um modo de convivência com a nova configuração democrática, ou pode conduzir, perante a rigidificação desse máximo, a uma ruptura ou, melhor, a uma sucessão histórica de micro-rupturas que apontem para uma ordem social pós-capitalista. Não é possível determinar qual será o resultado mais provável. A transformação social ocorre sem teleologia nem garantia. É esta indeterminação que faz o futuro ser futuro.

A renovação da teoria democrática assenta, antes de mais, na formulação de critérios democráticos de participação política que não confinem esta ao acto de votar. Implica, pois, uma articulação entre democracia representativa e democracia participativa."

Em “A crise dos Paradigmas em Ciências Sociais e os Desafios para o Século XXI", Boaventura de Sousa Santos (1999, p. 68-69), mais uma vez, retoma o tema da necessidade de revisão do modelo tradicional de democracia representativa, apontando o novo paradigma democrático para o novo século:

"Num espaço público em que o Estado convive com interesses e organizações não estatais, cuja atuação coordena, a democracia redistributiva não se pode confinar à democracia representativa, pois esta foi desenhada apenas para ação política nos marcos do Estado. Aliás, reside aqui o misterioso desaparecimento da tensão entre democracia e capitalismo neste final de século. Nas condições da nova constelação política, a democracia representativa perdeu as parcas virtualidades distributivas que alguma vez teve. Nas novas condições, a democracia redistributiva tem de ser democracia participativa, e a participação democrática tem de incidir tanto na atuação estatal de coordenação como na atuação dos agentes privados, empresas, organizações não governamentais, movimentos sociais cujos interesses e desempenho o Estado coordena. Em outras palavras, não faz sentido democratizar o Estado se, simultaneamente, não se democratizar a esfera não 
estatal. Só a convergência dos dois processos de democratização garante a reconstituição do espaço público de deliberação democrática."

Em outro livro intitulado "Democratizar a Democracia", Boaventura de Sousa Santos (2002, p. 75-76) aborda a questão da combinação entre democracia representativa e democracia participativa, apresentando as duas formas possíveis de efetivar essa combinação:

"A nosso ver existem duas formas possíveis de combinação entre democracia participativa e democracia representativa: coexistência e complementaridade. Coexistência implica uma convivência, em niveis diversos, das diferentes formas de procedimentalismo, organização administrativa e variação de desenho institucional. A democracia representativa em nivel nacional (domínio exclusivo em nível de constituição de governos; a aceitação da forma vertical burocrática como forma exclusiva da administração pública) coexiste com a democracia participativa em nível local, acentuando determinadas características participativas já existentes em algumas democracias dos países centrais (Mansbridge, 1990).

A segunda forma de combinação, a que chamamos complementaridade, implica uma articulação mais profunda entre democracia representativa e democracia participativa. Pressupõe o reconhecimento pelo governo de que o procedimentalismo participativo, as formas públicas de monitoramento dos governos e os processos de deliberação pública podem substituir parte do processo de representação e deliberação tais como concebidos no modelo hegemônico de democracia. Ao contrário do que pretende este modelo, o objetivo é associar ao processo de fortalecimento da democracia local formas de renovação cultural ligadas a uma nova institucionalidade política que recoloca na pauta democrática as questões da pluralidade cultural e da necessidade da inclusão social."

A indispensabilidade da correlação entre as formas representativa e participativa, para revigoramento da democracia, é também ressaltada por Antonio Carlos Wolkmer (2001, p. 35):

"Enfim, no novo paradigma de se fazer política não se está abandonando ou excluindo a democracia representativa e suas limitadas e insuficientes regras formais (partidos políticos, ação da maioria, votos, etc.), mas sim avançando e ampliando o processo mediante formas de democracia direta (participação orçamentária, gestão compartida e sistema de Conselhos) capazes de conviver com a democracia por delegação. A convergência dos processos democráticos tem de levar em conta, sobretudo, a participação comunitária, o controle dos cidadãos e a representação vinculante dos interesses em um novo espaço público, cujo palco privilegiado é o poder local." 
Em suma, a clara perda de legitimidade, de credibilidade e de eficácia da democracia representativa impõe o seu redimensionamento político com a agregação, por complementaridade, da dimensão participativa, o que descortinará, na ambiência plural da esfera pública, novas possibilidades de deliberação coletiva a respeito dos destinos das sociedades complexas. A formulação de políticas públicas na ambiência da democracia combinada ganha nova "procedimentalidade", passando a ser inspirada pelos influxos da representatividade política e da cidadania participativa, exercida nas diversas esferas públicas da sociedade. O filtro depurativo das escolhas públicas apresenta-se, dessa forma, mais eficaz (Frischeisen, 2001, p. 13).

Bresser Pereira $(1998$, p. 38$)$ em estudo sobre a sociedade civil, ressalta a importância da democracia participativa no processo de formulação de políticas públicas:

"No plano da sociedade civil existe, portanto, uma luta democrática e republicana para que esta assuma o papel de defensora dos direitos de cidadania, ao invés de se reduzir a uma elite que busca capturar o Estado para seus interesses privados. Para isto torna-se essencial aprofundar a democracia, não apenas aperfeiçoando os mecanismos institucionais que garantem a liberdade e a representação dentro do Estado, mas também envolvendo a democratizaçāo da própria sociedade civil. $\mathrm{Na}$ medida em que a sociedade civil se fortalece e se democratiza, logra transformar-se em agente estratégico da defesa dos direitos de cidadania e do interesse público. Este deixa de ser conceituado apenas de forma positiva ou formal como o interesse resguardado na lei aprovada pelos representantes do povo. Através da democratização da sociedade civil e do aprofundamento da democracia é possivel ir além desse consenso legal, e, aos poucos, ir construindo um conceito substantivo de interesse público.

Nas sociedades democráticas, o regime político democrático e as políticas públicas são em última análise fruto de um contrato social. Em um trabalho anterior procurei demonstrar que um problema fundamental das novas democracias nos países em desenvolvimento é a ausência ou a fragilidade desse contrato social (Bresser Pereira e Nakano, 1998). Cunill Grau (1998) enfatiza a necessidade de um novo contrato social para esses países, observando que não basta para isto termos uma 'democracia participativa', em que o terceiro setor tenha um papel crescente, dadas as assimetrias de representação ou de poder político. Para ela, é preciso pensar em uma reconceituação da participação cidadã, institucionalizando-a, e, nesse processo, estabelecer uma abertura expressa para os interesses sub-representados. Por outro lado, lembra ela que o Estado tem responsabilidades inafiançáveis, e salienta a necessidade de aumentar o poder da sociedade em relação aos monopólios de poder existentes no mercado (ou seja; na empresa capitalista) e no Estado (o poder dos políticos e burocratas). Dessa forma, ela está também se referindo à necessidade de democratizar a sociedade civil. $O$ aumento do espaço das organizações públicas não-estatais 
orientadas para o controle social, que ela tem estudado de forma criativa $e$ instigante, é uma parte desse processo. Através dele, a sociedade civil se autodemocratiza."

\section{A democracia da participação e o controle jurisdicional da formulação de políticas públicas}

O novo paradigma de democracia combinada abre espaço para o aprofundamento da participação popular no processo de formulação de políticas publicas. Entretanto, outro ângulo da questão merece ser examinado: aquele que enfoca a situação do cidadão como agente do controle de políticas públicas que venham contrariar princípios fundamentais abrigados no texto constitucional. Com efeito, a Constituição Federal brasileira de 1988 ampliou os mecanismos judiciais que podem ser utilizados pelos cidadãos na provocação do controle jurisdicional sobre a consistência das políticas públicas, que, em geral, são constituídas por escolhas discricionárias dos gestores públicos, informadas pelos critérios de conveniência e de oportunidade. Para um melhor entendimento sobre essa questão é preciso efetuar uma breve exposição a respeito do controle jurisdicional incidente sobre a ação do aparelho estatal.

$\mathrm{O}$ assunto controle jurisdicional dos atos administrativos é extremamente rico em conteúdo e polêmico em seus meandros. Mais controverso ainda quando incide sobre o controle dos atos administrativos discricionários, quanto aos limites e a densidade de sua perquirição. Com efeitos, decorridos mais de 210 anos da edição da Lei de 16-24 de agosto de 1790. que, na França, afirmou a separação das funções judiciárias e administrativas, proibindo a intervenção judicial nas atividades da administração, a questão do controle jurisdicional dos atos administrativos discricionários ainda figura como matéria de destaque no campo do debate doutrinário do Direito Administrativo. Embora aparentemente assentada, a teoria da discricionariedade dos atos administrativos e sua imunidade, quanto ao denominado mérito, ao controle jurisdicional, vem sofrendo, ao longo das últimas décadas, principalmente no plano internacional, fortes questionamentos sobre sua validade científica. De fato, a indiscutivel revitalização da principiologia constitucional e o fortalecimento da legitimação do Estado Democrático de Direito, para além das fronteiras meramente legalistas e formais descortinaram aos estudiosos novas perspectivas de análise e compreensão dos fenômenos jurídicos. Nesse cenário, de fértil motivação intelectual afloram, pouco a pouco, manifestações criteriosas que põem em xeque a intangibilidade do mérito dos atos administrativos discricionários.

Com relevo, deve ser destacada a atuação dos administrativistas espanhóis, além de alterações legais e procedimentais ocorridas na França com relação à atuação dos órgãos jurisdicionais do contencioso administrativo.'

1 Segundo Garcia de Enterría, lei francesa de 08 de fevereiro de 1995, sem fazer qualquer distinção entre a natureza discricionária ou vinculada do ato administrativo, autoriza os tribunais adminis- 
A clássica obra de García de Enterría, intitulada "La Lucha Contra las Inmunidades del Poder en el Derecho Administrativo ", publicada em 1974 pela Editora Civitas, em uma segunda edição (a primeira foi veiculada no $n^{\circ} 38$ da Revista de Administración Pública), pode ser tomada como um dos pilares que se ergueram contra o caráter intocável do poder discricionário.

No Brasil, após o advento da Constituição de 1988, o tema vem, progressivamente, ganhando a atenção dos doutrinadores administrativistas, estimulados por uma lufada de marcante cidadania que inspirou o processo de redemocratização nacional. Inúmeras obras jurídicas têm combatido, sem nenhum pudor intelectual, a arraigada doutrina da imunidade judicial do mérito dos atos administrativos discricionários, ainda defendida por grande parte dos estudiosos brasileiros do Direito Administrativo. Trabalhos apresentados por Eros Roberto Grau, Sérgio Ferraz e Juarez de Freitas exteriorizam a necessidade de ampliar o controle jurisdicional sobre os atos administrativos, "pois tanto os atos administrativos vinculados quanto os discricionários precisam, afinal, guardar conformação finalística plena com a íntegra do sistema positivado,..." 2

A jurisprudência nacional, alicerçada na visão de que a atuação administrativista deve ser coerente com os princípios abrigados no texto constitucional, tem imposto limites à atuação discricionária da Administração Pública, anulando atos contrários aos parâmetros da razoabilidade, proporcionalidade e do devido processo legal. Essa atuação do Poder Judiciário não resulta de uma opção política, discricionária, por assim dizer, da magistratura, ao contrário, ela revela a plena compreensão da força normativa da Constituição que impinge essa conduta judicial, controladora dos desbordamento da ação administrativa. Trecho do voto do Ministro Celso de Mello, proferido no julgamento do Mandado de Segurança ${ }^{\circ} 20.999$, pelo Supremo Tribunal Federal, em 21.03.90, patenteia o entendimento de que o ordenamento constitucional fornece respaldo jurídico para um controle jurisdicional mais efetivo da Administração Pública:

“É preciso evoluir cada vez mais no sentido da completa justiciabilidade da atividade estatal e fortalecer o postulado da inafastabilidade de toda e qualquer fiscalização judicial. A progressiva redução e eliminação dos círculos de imunidade do poder há de gerar como expressivo efeito conseqüencial, a interdição de seu exercício abusivo. ${ }^{3}$

trativos, se provocados, a determinar a execuçāo de específica providência funcional por parte da Administração, decorrente, essa medida, de anterior decisāo judicial. ENTERRÍA, Eduardo García de; Fernández, Tomáz-Ramon. Curso de Derecho Administrativo. Madrid: Editorial Civitas, 1998, p.476.

2 FREITAS, Juarez. O controle dos atos administrativos e os princípios fundamentais. São Paulo: Malheiros Editores, 1997. p.46.

3 Apud MEDAUAR. Odete. Controle da administração pública. São Paulo: Revista dos Tribunais, 1993. p.175. 
Recente modificação da Carta Política, ocorrida em 04 de junho de 1998, elevou à categoria de princípio constitucional, inserto no caput do art. 37 da Lei Fundamental, o parâmetro da eficiência. Essa alteração reforça o contexto de controlabilidade judicial dos atos administrativos discricionários, pois a aferição da eficiência exige, naturalmente, que se investiguem os motivos e o objeto da ação normativa estatal. "De nada adiantariam as noções de licitude e de eficiência administrativas se não houvesse os meios de permanente aferição do respeito a esses valores,..." 4

Dessa forma, em face do princípio universal da jurisdição, insculpido no art. $5^{\circ}$ da Constituição Federal, em seu inciso XXV, inexiste lugar jurídico inacessível à sindicabilidade do Poder Judiciário.

Assim, o processo de formulação de políticas públicas, bem como a concretude dessas políticas públicas, são passíveis de controle jurisdicional, provocado pelos cidadãos, sempre que venham a contrariar a principiologia tutelada pela Carta Política nacional. De fato, se o texto constitucional, em seu art. $3^{\circ}$, preconiza que, entre outros, constituem objetivos fundamentais da República Federativa do Brasil a construção de uma sociedade livre, justa e solidária e a erradicação da pobreza e da marginalização, quaisquer políticas que possam comprometer esses ideais são passiveis de correção judicial (Comparato, 1997, p.354).

Aqui a novidade a ser ressaltada não decorre da possibilidade do controle jurisdicional por descumprimento de normas legais, mas sim pela não observância dos ditames programáticos contidos nos princípios constitucionais, como, por exemplo, os princípios orientadores da atuação da Administração Pública, previstos no art. 37 da Constituição Federal. Os princípios constitucionais são "calibradores" impositivos da ação estatal, que condicionam as escolhas públicas. Não existe, para os formuladores de políticas públicas, liberdade indiscriminada de eleição de alternativas.

Celso Antônio Bandeira de Mello (1986, p. 230), conhecido jurista brasileiro, comentando a importância dos princípios constitucionais, como elementos de aferição da juridicidade do sistema normativo, fez as seguintes considerações:

"Princípio é, por definição, mandamento nuclear de um sistema, verdadeiro alicerce dele, disposição fundamental que se irradia sobre diferentes normas compondo-lhes o espírito e servindo de critério para sua exata compreensão e inteligência, exatamente por definir a lógica e a racionalidade do sistema normativo, no que the confere a tônica e lhe dá sentido harmônico (...) Violar um princípio é muito mais grave que transgredir uma norma. A desatenção ao principio implica ofensa não apenas a um específico mandamento obrigatório, mas a todo o sistema de comandos. É a mais grave forma de ilegalidade ou inconstitucionalidade, conforme o escalão do princípio

4 FERREIRA, Sergio de Andréia. A identidade da " função de controle da administração pública". In: ROCHA, Cármen Lúcia Antunes (org.). Perspectivas do Direito Público. Belo Horizonte: Del Rey, 1995. p.350. 
atingido, porque representa insurgência contra todo o sistema e subversão de seus valores fundamentais (...)

A qualidade e a eficiência na prestação dos serviços públicos figuraram como temas centrais do debate sobre o papel da Administração Pública nas sociedades modernas. Todos os programas de reformas administrativas, empreendidos nas duas últimas décadas, atribuíram relevância determinante a esses fatores, tomando-os como indicadores privilegiados para orientação do processo de remodelação da Administração Pública. Por consequiência, a permanente possibilidade de avaliação de políticas públicas resulta do próprio aprimoramento do aparelho estatal, não sendo vedada a verificação da consistência dessas políticas pelo Poder Judiciário.

\section{Conclusão}

A democracia representativa, como regime de organização política, enfrenta uma forte crise de legitimidade e de credibilidade. Na ambiência dos países periféricos essa crise é agravada por um quadro de formulação de políticas públicas em que o patrimonialismo e a privatização do Estado ainda se fazem presentes como elementos do processo político, em que pesem os esforços reformistas e estimuladores da transparência governativa.

A configuração de um novo paradigma de democracia combinada, que envolve a dinâmica representativa com a vertente da democracia participativa, abre novas perspectivas de formulação de políticas públicas possuidoras de legitimidade e de credibilidade.

O controle jurisdicional de políticas públicas, a partir de um prisma principiológico constitucional, demonstra-se juridicamente viável e politicamente exercitável, sendo uma das dimensões, no processo de formulação de políticas públicas, que merece aprofundamento analítico e relevo nas discussões acadêmicas.

\section{Bibliografia}

BRESSER PEREIRA, Luiz Carlos. Estratégia e estrutura para um novo Estado. Revista do Serviço Público, Brasília, ano 48, n 1, jan./abr. 1997. . Sociedade Civil: sua democratização para a Reforma do Estado.Texto para Discussão $n^{\circ}$ 32, Brasília, 1998.

BURSZTYN, Marcel. O país das alianças: elites e continuísmo no Brasil. Petrópolis, R.J: Vozes, 1990.

COMPARATO, Fabio Konder. Ensaio sobre o juízo de constitucionalidade de políticas públicas. In: Mello, Celso Antônio Bandeira (org.) Estudos em homenagem a Geraldo Ataliba. São Paulo: Malheiros Editores, 1997.

DELGADO, Daniel Gárcia. Estado-nación y globalización. Buenos Aires: Ariel. 1998. 
ENTERRÍA, Eduardo García de: Fernández, Thomas - Ramon. Curso de derecho administrativo. $8^{\text {a }}$ ed. Madrid: Editorial Civitas, 1998.

La lucha contra las inmunidades del poder (poderes discrecionales, poderes de gobierno, poderes normativos). $2^{2}$ ed. Madrid: Editorial Civitas. 1994.

FAORO, Raymundo. Os donos do poder: a formação do patronato político brasileiro. $3^{\mathrm{a}}$ ed. São Paulo: Editora Globo, 2001.

FERREIRA, Sérgio de Andréia. A identidade da função de controle da administração pública. In: Rocha, Cármen Lúcia Antunes (org.).Perspectivas do Direito Público. Belo Horizonte: Del Rey, 1995.

FREITAS, Juarez. O controle dos atos administrativos e os princípios fundamentais. São Paulo: Malheiros, 1997.

FRISCHEISEN, Luzia Cristina Fonseca. Ministério Público e Conselhos Gestores de Políticas Públicas. Boletim dos Procuradores da República, ano IV, $\mathrm{n}^{\circ} 38$. jun. 2001.

HIRST, Paul. A democracia representativa e seus limites. Rio de Janeiro:Jorge Zahar, 1992.

MEDAUAR, Odete. Controle da administração pública. São Paulo: Revista dos Tribunais, 1993.

MELLO, Celso Antonio Bandeira de. Elementos de direito administrativo. São Paulo: Revista dos Tribunais, 1986.

O'DONNELL, Guilhermo. Democracia delegativa? Novos Estudos CEBRAP, São Paulo, no 31, p. 25-40, out. 1991.

SANTOS, Boaventura de Sousa. Pela mão de Alice: o social e o político na pósmodernidade. $2^{a}$ ed. São Paulo: Cortez, 1996.

Reinventar a democracia: entre o pré-contratualismo e o pós-contratualismo. In: Heller, Agnes (org.). A crise dos paradigmas em ciências sociais e os desafios para o século XXI. Rio de Janeiro: Contraponto, 1999.

- Democratizar a democracia: os caminhos da democracia participativa. Rio de Janeiro: Civilização Brasileira, 2002.

WOLKMER, Antônio Carlos. Do paradigma político da representação à democracia participativa. Seqüencia, n 42, jun. 2001. 